\title{
Smart Health Pregnancy by Augmented Reality: An Interactive Guide for Embryo Growth Using Multi-Marker
}

DOI:10.36909/jer.ASSEEE.16095

Selvia Lorena Br Ginting*, F D Agnia**, Y R Ginting***

*Department Sistem Komputer, Universitas Komputer Indonesia

** Department of Mechanical Engineering , Universitas Riau, Kampus Bina Widya KM 12,5, Simpang Baru, Pekanbaru 28293, Indonesia

*** Department of Mechanical Engineering, Curtin University, Kent St, Bentley WA 6102.

*Corresponding Author: selvia.lorena@email.unikom.ac.id

\begin{abstract}
This research aims to create Smart Health Pregnancy software that educates pregnant women on fetal development. During pregnancy, a pregnant woman's health highly influences the pregnancy success rate. Thus, knowing the pregnancy process is necessary for pregnant women. Although resources concerning fetal development such as textbooks, general articles, and websites can be accessed easily, these resources are often too condensed with text, have a less interactive display, and provide inadequate information. Therefore, Smart Health Pregnancy software would facilitate pregnant women in understanding fetal development, displayed in an interactive way using Augmented Reality (AR) technology. The AR method utilized is a marker-based tracking method where the user can use an Android smartphone camera to receive a marker that can display a virtual object in the real world. The virtual object is presented in the form of the embryo or fetus from 1 to 38 weeks in 3D. Furthermore, important information regarding fetal development and the health of pregnant women is also shown. From the results, $95 \%$ of the respondents stated that this software is user-friendly and very informative. It shows that the software has performed well and can educate pregnant women.
\end{abstract}

Keywords: Augmented Reality, Health, Pregnancy, Multi-Marker 


\section{INTRODUCTION}

Pregnancy is an important aspect of the continuation of human life (Hermina, C. W., and Wirajaya, A. 2015). Pregnancy is also an important event in a woman's life as she has a developing fetus in her womb (Notonegoro, Y. 2019). The process of pregnancy is a long journey until the child in the womb is born into the world (Hermina, C. W., and Wirajaya, A. 2015). In this long pregnancy process, the health condition of the expectant mother from the beginning to the end of pregnancy greatly affects the success rate of pregnancy itself (Hermina, C. W., and Wirajaya, A. 2015; Notonegoro, Y. 2019). Likewise, the health status of a prospective baby who is still in the womb, even when it is born, is greatly influenced by the health of the prospective mother during pregnancy (Hermina, C. W., and Wirajaya, A. 2015; Notonegoro, Y. 2019; Varsier, N. et al., 2014). Therefore, expectant mothers need to adopt a healthy lifestyle and understand what the mother and baby need in the pregnancy process (Hermina, C. W., and Wirajaya, A. 2015; Notonegoro, Y. 2019; Varsier, N. et al., 2014). The knowledge that can affect pregnancy is antenatal care, signs of pregnancy, food intake (nutrition or supplements), and medicines. In undergoing pregnancy, pregnant women must have this knowledge in facing nine months of pregnancy so that the fetus in the womb can develop properly (Hermina, C. W., and Wirajaya, A. 2015). However, human fetal development can be found in textbooks, general articles, and websites for pregnant women. The information presented using text and images looks less attractive and less interactive due to too much explanatory text and only a few pictures (Martin, J., Bohuslava, J., and Igor, H. 2018). Likewise, websites also have their shortcomings, which are the requirement of internet connection and have interfaces that sometimes are unattractive for the public (Martin, J., Bohuslava, J., and Igor, H. 2018; Rahmat, R. F. et al., 2018). Therefore, an interactive and informative application that can educate pregnant women about fetal development and important information based on the age of the fetus itself is required. In this study, an Android-based application was built that applies Augmented Reality technology that can present interactive visualizations (Amin, D., and Govilkar, S. 2015; Kim, Y. G., and Kim, W. J. 2014; Afandi, B., Kustiawan, I., and Herman, N. 2019). Augmented Reality (AR) is a technology that combines twodimensional and/or three-dimensional virtual objects into a real three-dimensional environment and then projects these virtual objects in real-time (Amin, D., and Govilkar, S. 2015; Kim, Y. G., and Kim, W. J. 2014; Afandi, B., Kustiawan, I., and Herman, N. 2019; Ginting, S. L., Adler, J., and Aditama, W. 2017). 
There have been many previous studies with various cases that apply Augmented Reality technology. Hong Zeng et al. built an application for piano learning by considering pair players based on multi-marker tracking. The study results indicated that multi-marker tracing resulted in more stable and clearer augmentation (Zeng, H., He, X., and Pan, H. 2019). Second, similar research by Rahmat R F and his colleagues uses Augmented Reality to educate hijaiyah (Arabic) letters with a single marker technique with a marker-based tracking method. The application built displays interactive learning and becomes something new for children to foster children's interest in learning (Rahmat, R. F., et al., 2018). Research by Ginting et al. applied a multi-marker technique by detecting several markers at the same time. This study shows that the multi-marker technique can simplify 3D objects displaying processes and provide stimulation information for babies 0 to 12 months (Ginting, S. L., et al., 2017).

Based on these previous studies, it appears that Augmented Reality technology has the advantage of being more interactive and effective in its use, especially in terms of learning or education. On the other hand, Augmented Reality marker detection can be done easily to feel comfortable using this application. Furthermore, in terms of visualization, the shape of the fetus is similar to the original form since Augmented Reality technology can display interactive 3D objects so that users would be attracted to use this application. The application built is called Smart Health Pregnancy. Using Augmented Reality technology, this Smart Health Pregnancy application can provide a simple and attractive display (Ginting, S. L., et al., 2017; Zeng, H. et al., 2019; Tomi, A. B., and Rambli, D. R. A. 2013). This technology can make it easier to display 3D fetal object visualization with more stable and clear results (Zeng, H. et al., 2019). The detection method used is the marker-based tracking method, which functions to facilitate marker detection. There are 33 markers (multi markers) made in this study. Multi marker is a technique that allows the detection of many objects that can come out in one marker detection time Tomi, A. B., and Rambli D. R. A. 2013; Lai, C. L., and Wang, C. L. 2012). This study also adds important information to educate pregnant women, including information on what expectant mothers should do and what mothers and fetuses need during pregnancy. Furthermore, information on caring for pregnancy is also provided, including a healthy lifestyle and information regarding fetal development (along with displaying the shape of the fetus in 3D) according to age. The information and shape of the fetus displayed are based on the development in each week from the beginning of pregnancy to 9 months. 


\section{METHOD}

\section{Augmented Reality}

Augmented Reality is an interactive technology that combines 2D and/or 3D virtual objects into a real 3D environment, and then these virtual objects are projected into a real-time environment. Augmented Reality characteristics are not limited to using sight alone. Augmented Reality (AR) allows the user to interact with the real world. It is also expressed as an environment where multi-media features such as text, image, sound, video, animation, the hologram can be integrated into real and virtual objects, as well as 2dimensional (2D) or 3- dimension (3D) features (Lai, C. L., and Wang, C. L. 2012; Chao, J. T., Pan, L., and Parker, K. R. 2014; Adrianto, D., Hidajat, M., and Yesmaya, V. 2017)

\section{Marker Based Tracking}

Augmented Reality Marker (marker-based tracking) is an augmented reality technology that illustrates a white and black square with a thick black frame on a black and white background. In the computer depiction, the size of $631 \times 634$ pixels is the standard size of a marker. The computer will identify the orientation and position of the marker, which will create a three-dimensional virtual world with $\mathrm{X}$, Y, and Z axes with points (0,0,0). (Rahmat, R. F., et. al., 2018; Amin, D., and Govilkar, S. 2015; Alper, A., Öztaş, E. Ş., Atun, H., Çınar, D., \& Moyenga, M. 2021)

\section{Vuforia SDK}

Vuforia is a Software Development Kit for smartphone devices used in creating Augmented Reality software. Qualcomm created Vuforia SDK to meet the needs of developers to create Augmented Reality applications. The Vuforia SDK has been successfully used in various Augmented Reality mobile applications. Vuforia SDK supports 2D and 3D objects, including multiple target configurations, images with fewer symbol and frame tags. There is an added function in the SDK. It takes advantage of virtual buttons to detect localized occlusion. Moreover, it can select and reconfigure the target image in real-time and create a target set according to the scheme. 
The data stream of Vuforia SDK is divided into four modules: inputting, database, tracking, and matching and render output. Mobile phones can seize images of each frame in the present real scene through the camera and then matches identification objects in the database timely according to the pixel format conversion. It adds preset virtual objects such as 3D models, animation, or video to real scenes. It can also interact with these virtual objects, render and output information at mobile terminals (Amin, D., and Govilkar, S. 2015; Adrianto, D. et al., 2017; Sural, I. 2018; Liu1, X., Sohn, Y. H., \& Park, D. W. 2018)

\section{Unity 3D}

Unity 3D is a cross-platform integrated 3D game engine developed by Unity Technologies Co.Ltd. It can superpose the virtual onto reality and realizes human-computer interaction with some AR development tools. It allows Vuforia SDK extension plug-ins to detect and track under the corresponding ports and creates AR applications and games. It provides ample development box functions to create games and other interactive 3D content. Unity 3D can append sunlight, fog, wind, skybox, water, and other physical materials, ambient sound, and animated video to the virtual scene. Meanwhile, you can browse, test, and edit 3D application scenarios. Also, it is available to release to the required platforms, such as Windows, iOS, Android, and so on. (Liu1, X., Sohn, Y. H., \& Park, D. W. 2018)

\section{FAST Corner Detection Algorithm}

FAST (Features From Accelerated Segment Test) Corner Detection Algorithm is created to accelerate real-time computation time with the consequence of reducing the accuracy of corner detection (Ahmadi, R. A., et al., 2017; Suran, K. 2014). The FAST Corner Detection algorithm works on an image, and how it works can be seen as follows:

1. Determine a point $\mathrm{p}$ on the image with the initial position (Xp, Yp) as shown in Figure 1 (Ahmadi, R. A., et al., 2017). 


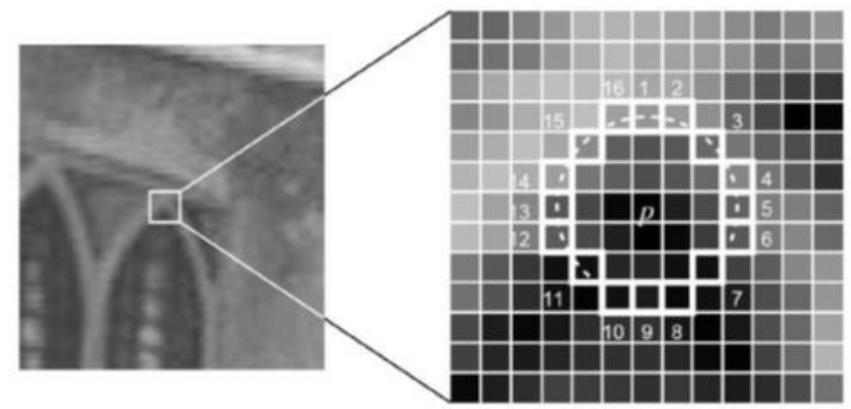

Figure 1 Image of starting position

2. Determine the four points. The first point $(n=1)$ lies at the coordinates $(X p, Y p+3)$, the second point $(n=2)$ is located at the coordinates $(X p+3, Y p)$, the third point $(n=3)$ is located at the coordinates $(X p, Y p-3)$, the fourth point $(n=4)$ lies on the coordinates $(X p-3, Y p)$ (Ahmadi, R. A., et al., 2017).

3. It was comparing the intensity of the center point $p$ with the four surrounding points. If there are at least 3 points that meet the requirements found in step 2, then the center point $\mathrm{p}$ will be the vertex, as shown in Figure 2 (Ahmadi, R. A., et al., 2017).

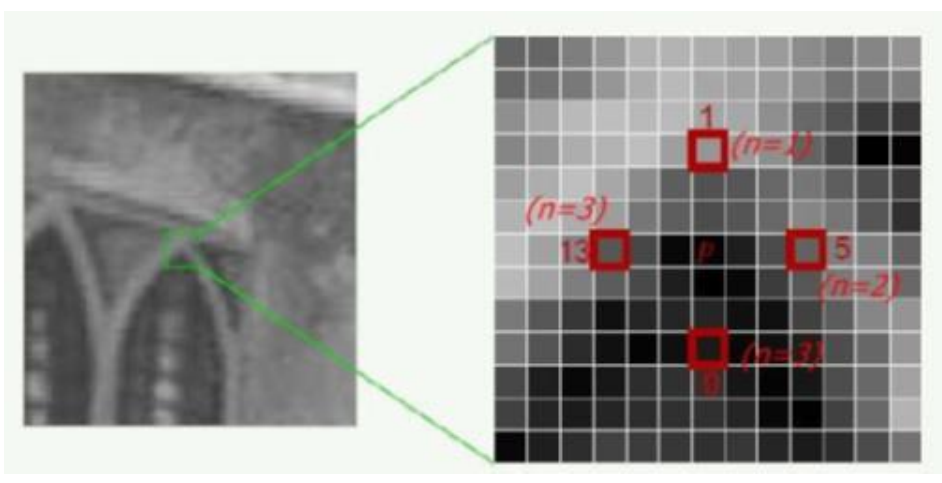

Figure 2 The four coordinate points

4. To determine the point of an angle, all pixels will be divided into three subsets, namely: Pixel dark, Pixel similar, and Pixel brighter (Amin, D., and Govilkar, S. 2015; Ahmadi, R. A., et al., 2017).

5. The process repeated until all points on the image has been compared in intensity, as shown in Figure 3 (Ahmadi, R. A., et al., 2017). 


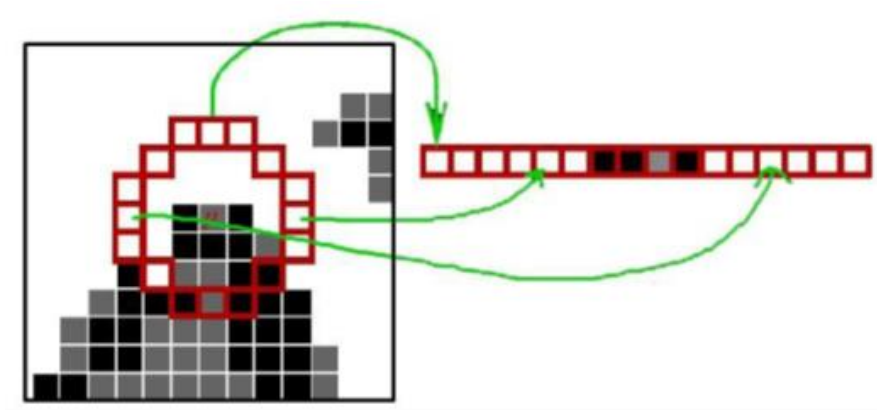

Figure 3 Three points are eligible

Vuforia uses the FAST Corner Detection algorithm to define how well images can be detected and tracked using the Vuforia SDK. The higher the augmentable rating of the image target, the stronger the detection and tracking capabilities it contains (Aisyah, Bukit N., and Derlina. 2020). Augmentable ratings can range from 0 to 5 for each rendered image. If a rating shows 0 , it proves the target is not detected by the Augmented Reality system, while a 5-star rating indicates that the Augmented Reality system easily tracks an image.

\section{RESULTS AND DISCUSSION}

This study discusses the findings of using Augmented Reality-based learning. The findings of existing studies indicate that Augmented Reality technology has potentials in healthcare usage. Augmented reality essentially helps the environment experiment, studies that are dangerous and cannot be realized in real life. In addition, Augmented Reality can be simulated in difficult and dangerous situations from the real world. Likewise, a pregnant woman cannot see her fetus directly to obtain information on its development. Therefore, with the correct technology, education or learning about pregnancy can be optimized.

In this context, learning or education about health can be considered. The potential for learning using Augmented Reality can increase interest and skills, giving positive effects on motivation and performance. This study will explain the important role of Augmented Reality in increasing the effectiveness and efficiency of healthcare. The explained data testing is attached in the results and discussion section. The discussion utilizes the Fast Angle Detection algorithm, which functions to see the feasibility process of a marker so that the resulting marker would determine the quality of the application. Then, the 
implementation of the algorithm is tested, so aspects of the planned implementation discussed in this section are known.

\section{Implementation of Augmented Reality}

This stage is where the Smart Health Pregnancy application can be used and run. This testing stage will explain the implementation of Augmented Reality in the application. This implementation is used as an indicator to determine whether or not the application was made according to plan. Furthermore, this stage measures the extent to which Augmented Reality can be applied in pregnancy education and what benefits are gained through Augmented Reality.

\section{Fast Corner Detection Algorithm}

At this stage, it shows how well the image can be detected and tracked using the Vuforia SDK (Rahmat, R. F., et al., 2018; Amin, D., and Govilkar, S. 2015). The augmentable rating of the target image and all image analysis results/markers that have been uploaded to https://developer.vuforia.com as shown in Table 1.

Table 1 Low Feature and High Feature Analysis Images

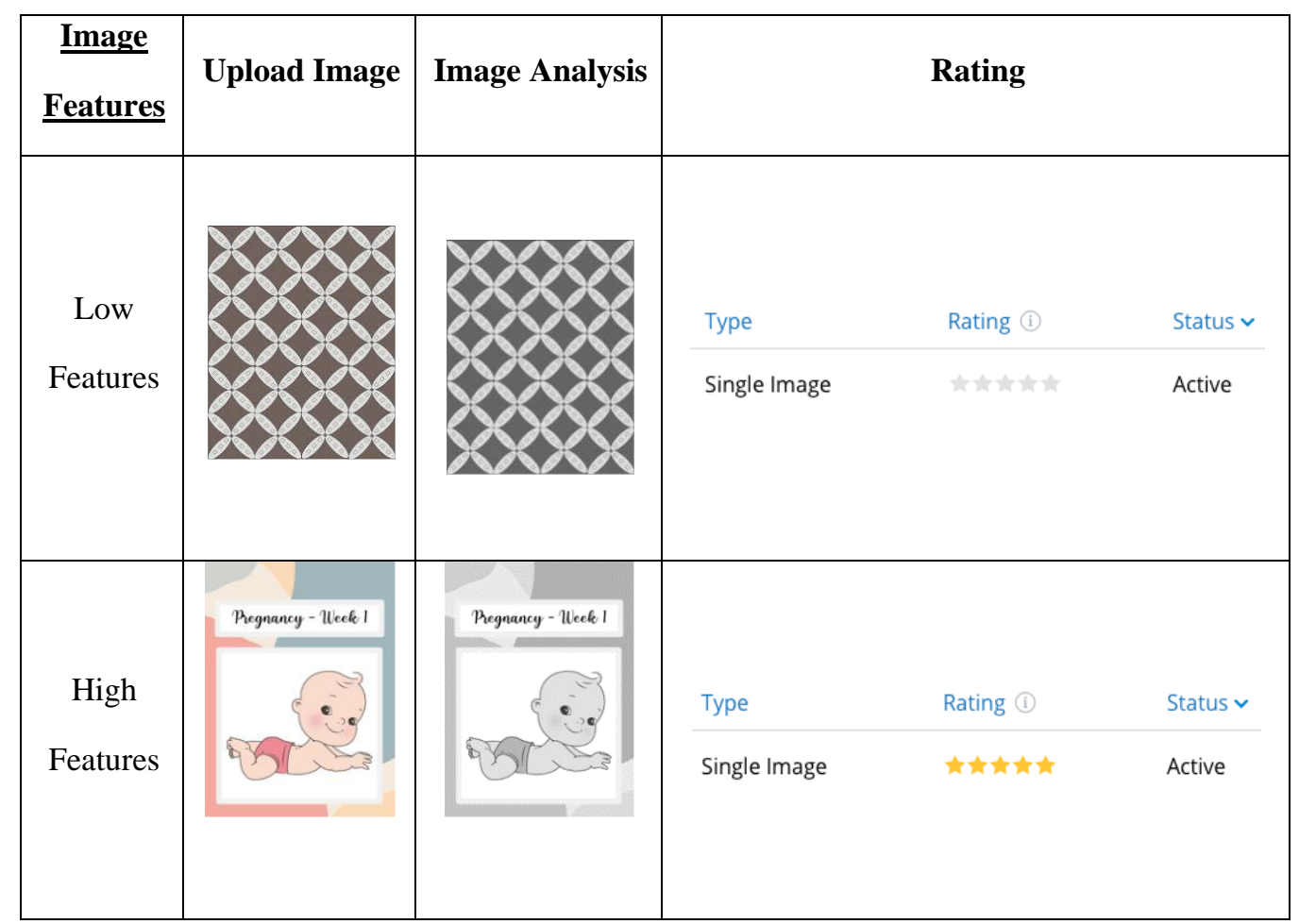

The low feature images have a low star rating indicating that although the image contains sufficient features and good contrast, the repeating pattern hinders the detection performance. For best 
results, choose images without repeating motifs (even if rotated in scales) or strong rotational symmetry. A circle is an example of repeating patterns. This pattern appears the same so that the detector feature can detect it. High-rated images are images that have many angles. The more balanced the distribution of features in an image, the better it can be detected and traced. Consider cropping the image to remove featureless areas. Therefore, the rating shows a five-star result for high features, and vice versa for low features gets a zero rating.

Furthermore, testing the cut marker image is shown in Table 2. It is shown that when an image or marker is cut, it can reduce the image's rating since the information in the image is incomplete. With each cropped image, the information is reduced since the features in the image are few. Then the rating shows zero-star results.

Table 2 Crop Images for Features Distribution

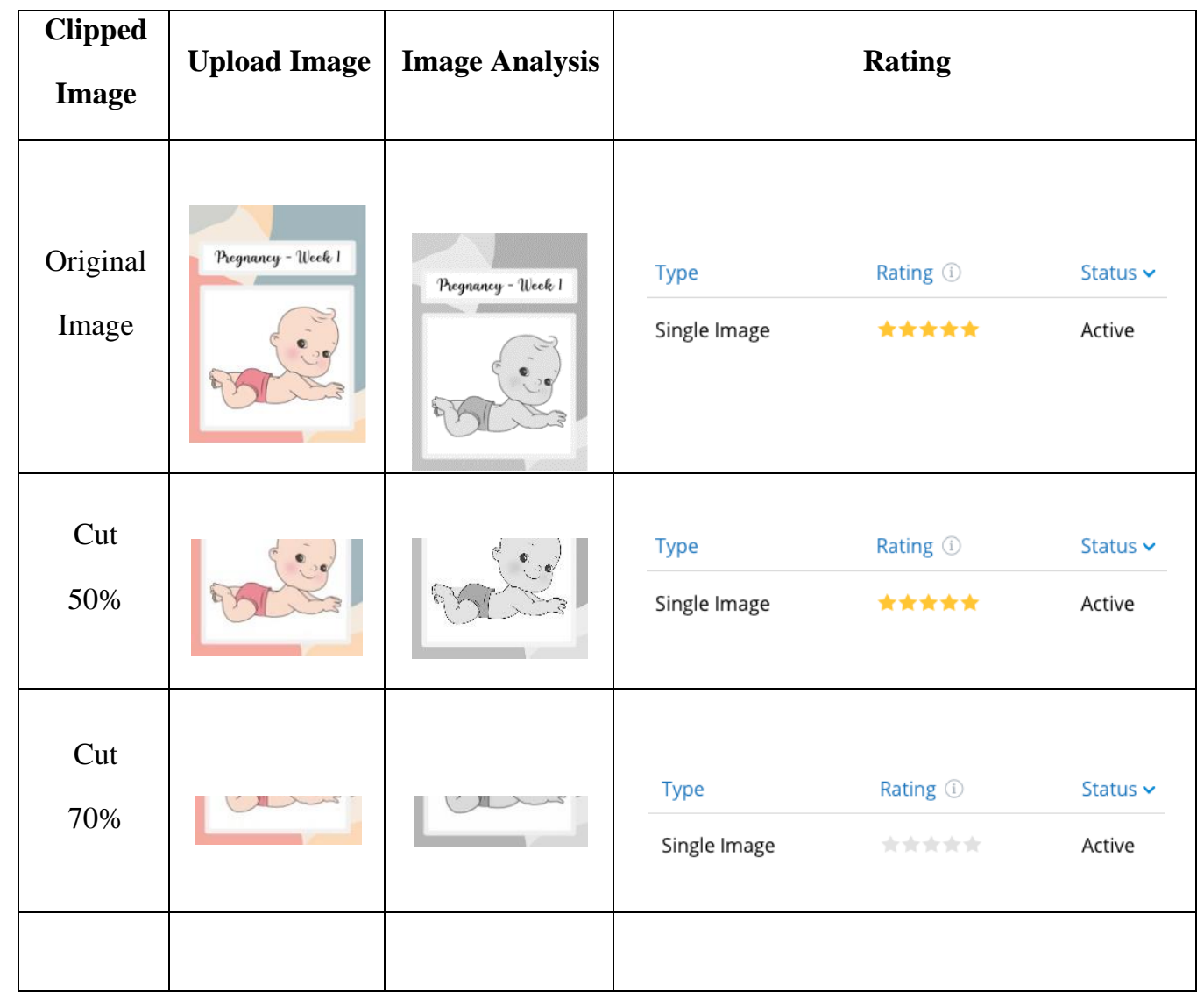

Then, light-based marker testing in table 3 is carried out to determine if the bright light or no light determines when the marker detects it can be read or not read. From the results of this test, it can be 
concluded that when the light is on, 3D objects can be displayed, and when the lights are off, 3D objects cannot be displayed. In this case, the scanning camera cannot perform the scan process in a dark room. Since this research uses marker-based tracking, the application cannot reveal 3D objects in the dark. When the camera performs the detection, the marker is not visible, and thus the algorithm does not work. If there is light, the 3D object appears because the algorithm can detect markers to display $3 \mathrm{D}$ objects as requested by the user.

Table 3 Marker Detection Image by Image

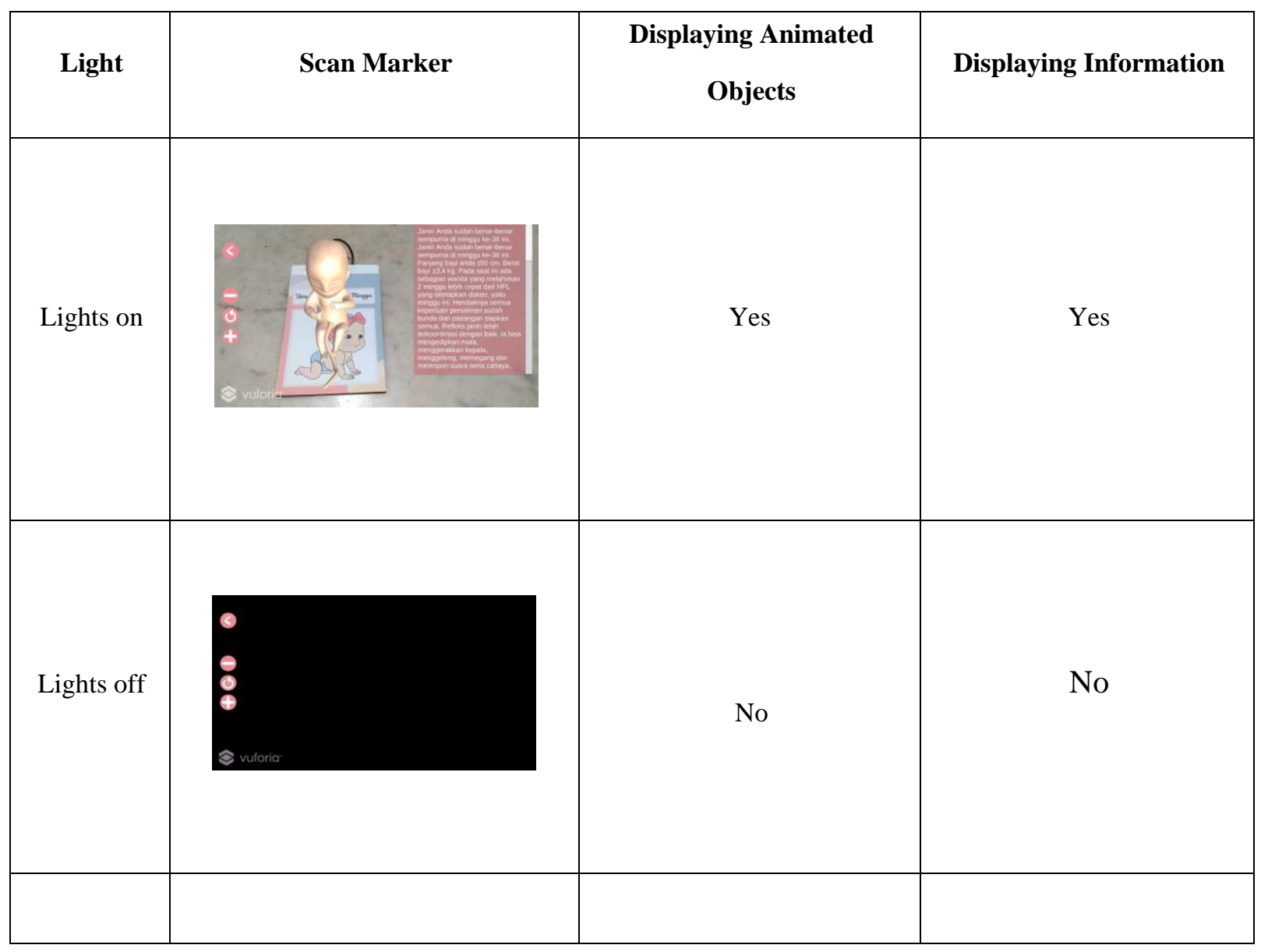

Next is testing the marker detection based on the camera tilt in table 4. After tilting the camera at angles of $0^{\circ}, 15^{\circ}, 30^{\circ}, 45^{\circ}$, and $60^{\circ}$, it is found that the maximum detection of the marker is $45^{\circ}$. If the tilt exceeds $45^{\circ}$, the camera cannot detect the marker because the marker is not recognized or read properly. This test is carried out to determine how many angles can be detected and which angles cannot be detected. 
Table 4 Marker Detection Picture Based on the Till of the Camera

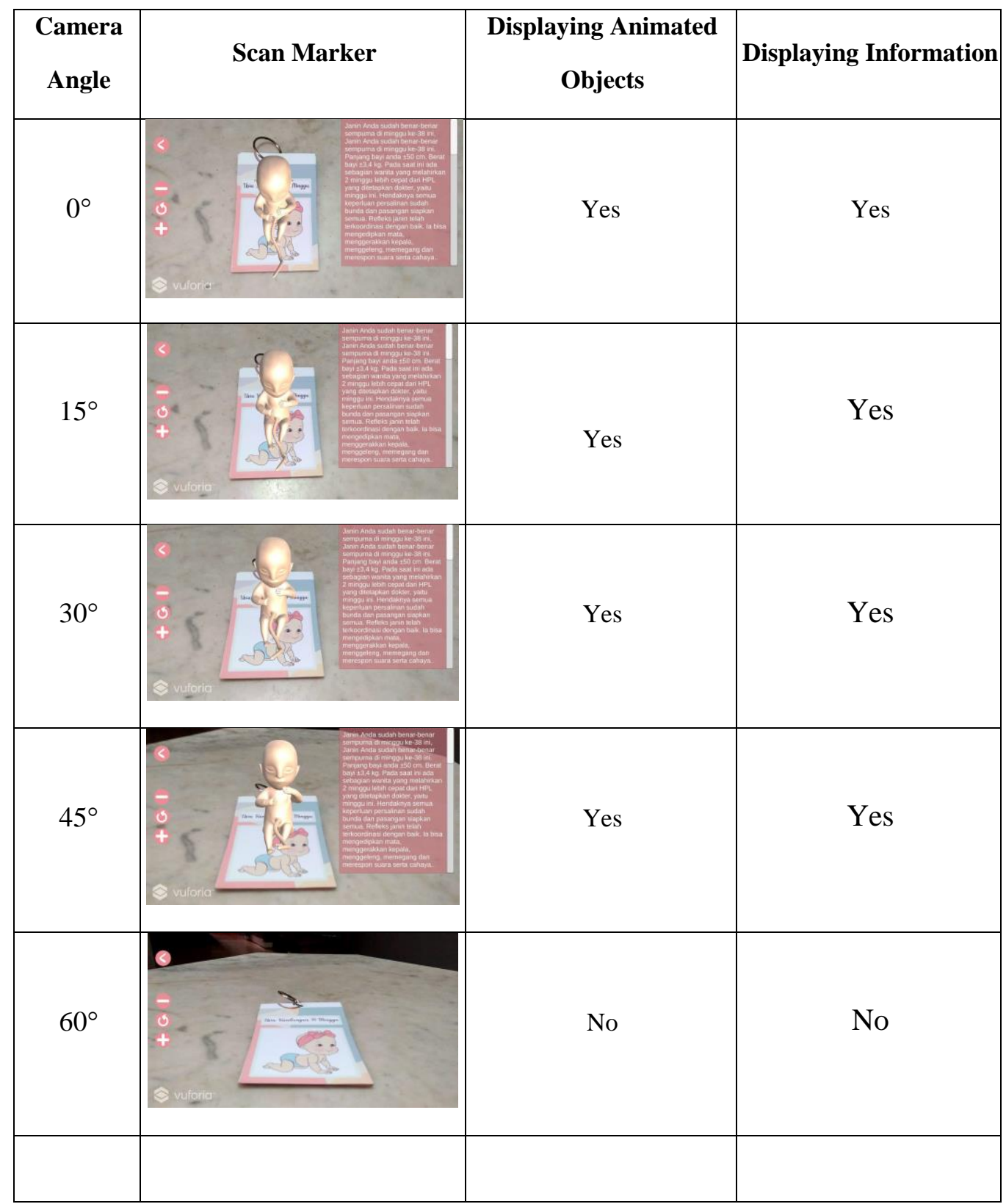

\section{Multi-Marker Tracking}

The marker in Figure 4 is an example of Augmented Reality markers (33 markers) used in the Smart Health Pregnancy application. There are two methods in marker detection, namely the one marker method (single marker) and many markers (multi-marker). Single marker only detects one image used as a marker media, and only one object will come out. Multi-marker is a method that allows the detection of many objects that can come out in one marker detection time. Rahmat, R. F., et al., 2018; Lai, C. L., and Wang, C. L. 2012; Arifitama, B. et al., 2019). Multi-marker is a development 
from a single marker, where there is more than one tracking marker camera (Amin, D., and Govilkar, S. 2015). The marker used in the development of this application is images of types of babies in the form of animated cartoons, baby items, and numbers. Markers made in this application are 33 markers as detection objects. The followings are examples of markers that have been made and used in the application.

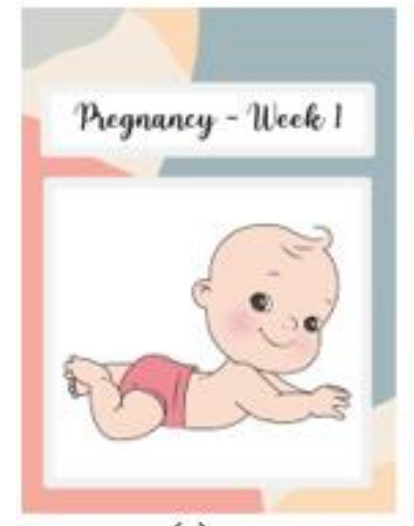

(a)

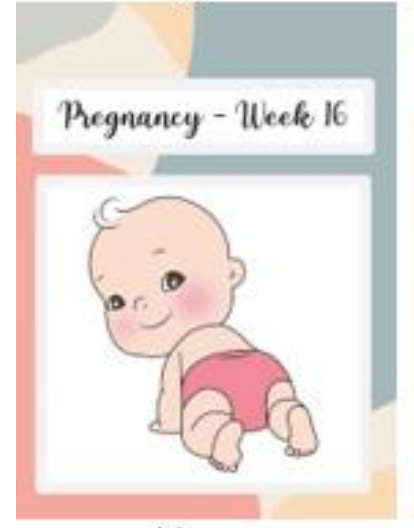

(c)

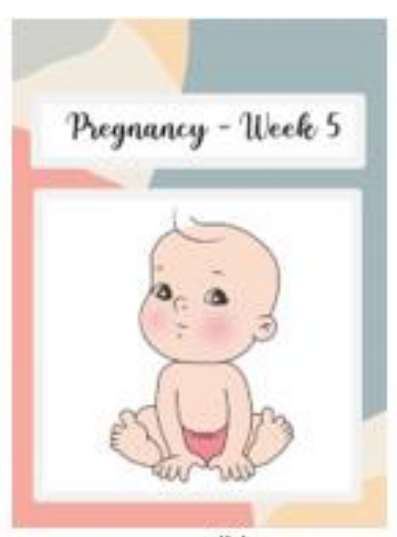

(b)

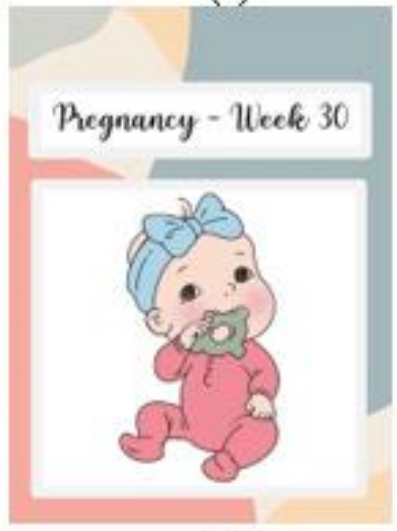

(d)

Figure 4 (a), (b), (c), and (d) Augmented Reality Markers

\section{Test Result}

The work process of the application software is to use an Android smartphone camera as a tool in the search and detection of markers using the FAST Corner Detection algorithm. The marker will be tracked via the Android smartphone camera. After the camera catches the marker, the tracking process is carried out to determine whether the marker matches the previously configured marker. This process is done by detecting corners through FAST Corner Detection in the Vuforia library.

If the markers match, the software system will display a 3D object that matches the content inside the marker. However, if the camera does not detect an object angle detection within the marker, the camera 
will not display a 3D object (Adrianto, D. et al., 2017; Bostanci, E. et al., 2013). If the rating on the marker has high accuracy, the FAST Corner Detection algorithm will track and display 3D objects on the marker, as shown in Figure 5.

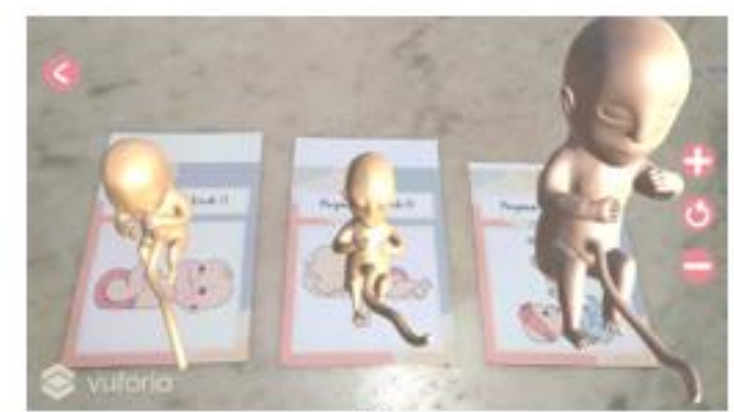

(a)

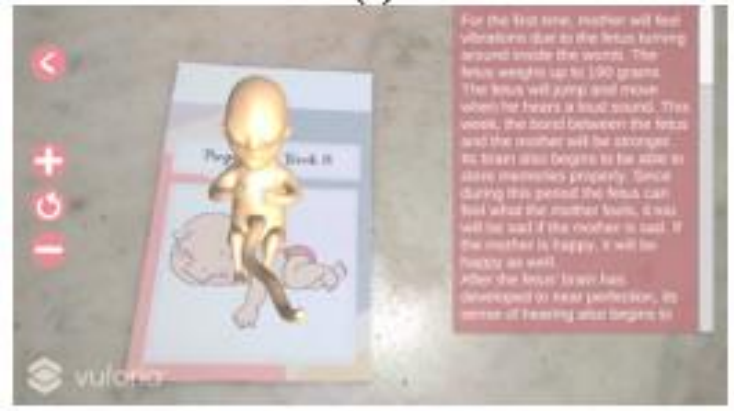

(c)

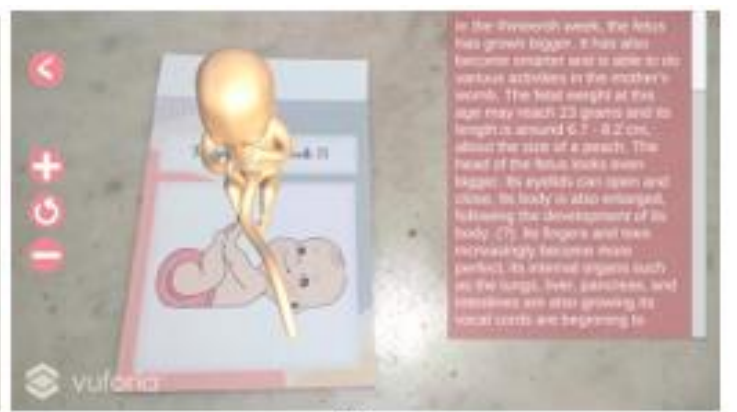

(b)

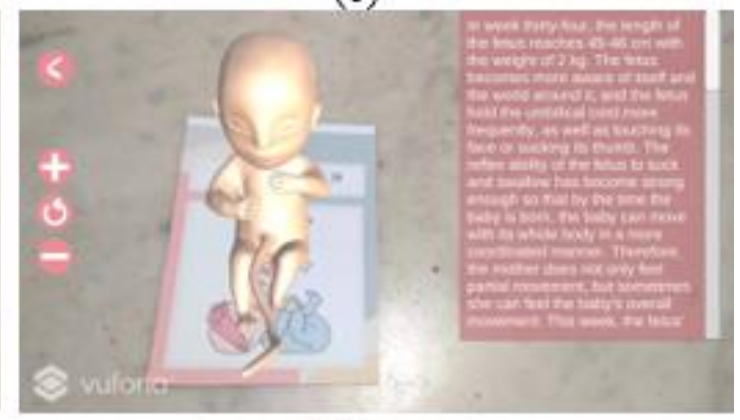

(d)

Figure 5 (a) Multi-marker display, (b), (c) and (d) Display fetus growth information

Figure 5(a) is a display of fetal development using a multi-marker technique. Several markers were detected and resulted in an outline of fetal development in pregnant women. The picture shows how the camera can simultaneously detect markers and bring up objects according to the marker chosen by the pregnant woman (Suran, K. 2014).

Figure 5(b), 5(c), and 5(d) is the display when a pregnant chooses an option based on the age of the fetus. This feature will display text on the right-hand side in information on fetal development and pregnancy that educates the pregnant woman.

Some of the marker tests carried out are to determine the performance of Augmented Reality in providing the effectiveness of displaying 3D objects. Markers are fundamentally a very important part of Augmented Reality. This research shows that the markers created require the developer to analyze it according to the regulations used as a standard on Vuforia. The reference is how many angles are in the image and avoiding the use of markers with the same pattern so the detection will be stable. The technique 
of using multi-markers gives the maximum effect in using Augmented Reality since one marker that is scanned using an Android camera will display only one object. That way, the results will be stable, particularly for displaying objects and pop-up information.

This research study describes the use of Augmented Reality by using multi-marker tracking, where the multi-marker is used as a tool to display 3D objects. Besides, users can see the shape of the fetus by using the zoom in, zoom out, and rotation features. This study focuses on the consistency of the use of multimarkers that can make it easier for users to detect markers. Thus, the results are just as expected and useful for users to understand an object that cannot be seen in real life on the screen of a supporting device (Android) with the Augmented Reality application installed. This application focuses on educating pregnant women to see the conditions of their fetuses by looking at the information available in the application. However, applications that apply Augmented Reality technology aim to add virtual objects, not replace real objects.

The test results show that this application complements the previous studies. The multi-marker technique used displays the shape of the fetus as a $3 \mathrm{D}$ object so that it is clearer and more stable during marker detection. This application is also more equipped other than displaying 3D objects. It also displays information that educates pregnant women (Rahmat, R. F., et al., 2018; Ginting, S. L., et al., 2017; Zeng, H. et al.,). The information displayed is based on gestational age, every week from 0 to 9 months of pregnancy.

A test to see user satisfaction is carried out by distributing questionnaires to 30 respondents consisting of pregnant women who have used the Smart Health Pregnancy application. The questionnaire results show that $95 \%$ of the respondents strongly agree that this application helps pregnant women gain knowledge concerning pregnancy.

\section{CONCLUSION}

Based on the results obtained in testing the multi-marker technique using FAST Corner Detection, it can be concluded that the application can easily detect markers and display fetal development in 3D according to the age of the womb. Besides that, complete information is displayed every week from 0 to 9 
months, educating pregnant women. This application can provide good education, similar to the previous studies. Based on the test analysis that has been carried out, it can be stated that the application provides maximum results. The Smart Health Pregnancy application in the form of a mobile application can interactively educate pregnant women regarding fetal development and information on the pregnancy itself. Augmented Reality with real-time multi-marker techniques in this application makes it easier for users to use this application since it can detect multiple markers simultaneously and display results that are easy to understand for pregnant women. It is proven that $95 \%$ of pregnant women respondents who have used this application stated that this application is easy to use, understandable, and very informative.

\section{ACKNOWLEDGMENT}

We would like to thank Universitas Komputer Indonesia for supporting this journal.

\section{REFERENCES}

Hermina, C. W., and Wirajaya, A. 2015. Hypnobirthing The Conny Method: Menjalani Kehamilan dan Persalinan dengan Nyaman, Tenang, Bahagia, dan Penuh Percaya Diri Jakarta: PT Gramedia Pustaka Utama

Notonegoro, Y .2019. Amazing! Kehamilan Bunda Dalam 9 Bulan Depok: Senja Media Utama

Varsier, N. et. 1. 2014. Influence of Pregnancy Stage and Fetus Position on The Whole-Body and Local Exposure of The fetus to RF-EMF Physics in Medicine and Biology. 59(17): 4913-4926.

Martin, J.,Bohuslava, J., and Igor, H. 2018. Augmented Reality in Education 4.0 2018 IEEE 13th International Scientific and Technical Conference on Computer Sciences and Information Technologies. CSIT 2018, 1: 231-236.

Rahmat, R. F., Akbar, F., Syahputra, M. F., Budiman, M. A., and Hizriadi, A. 2018. An Interactive Augmented Reality Implementation of Hijaiyah Alphabet for Children Education. Journal of Physics: Conference Series, 978(1): 012102.

Amin, D., and Govilkar, S. 2015. Comparative Study of Augmented Reality Sdk's. International Journal on Computational Science \& Application,s 5(1): 11-26.

Kim, Y. G., and Kim, W. J. 2014. Implementation of Augmented Reality System for Smartphone Advertisements. International Journal of Multimedia and Ubiquitous Engineering, 9(2): 385-392. 
Afandi, B., Kustiawan, I., and Herman, N. 2019. Exploration of The Augmented Reality Mode in Learning. Journal of Physics: Conference Series, 1375(1): 012082.

Ginting, S. L., Adler, J., and Aditama, W .2017. Augmented Reality Sebagai Media Pembelajaran Stimulasi Bayi. Jurnal Manajemen Informatika, 1(13): 1-14.

Zeng, H., He, X., and Pan, H. 2019. FunPianoAR: A Novel AR Application for Piano Learning Considering Paired Play Based on Multi-Marker Tracking. Journal of Physics: Conference Series, 1229(1): 010272.

Tomi, A. B., and Rambli, D. R. A. 2013. An interactive mobile augmented reality magical playbook: Learning number with the thirsty crow. Procedia Computer Science, 25: 123-130.

Lai, C. L., and Wang, C. L. 2012. Mobile Edutainment With Interactive Augmented Reality Using Adaptive Marker Tracking Proceedings of the International Conference on Parallel and Distributed Systems - ICPADS; 124-131.

Chao, J. T., Pan, L., and Parker, K. R. 2014. Campus Event App - New Exploration for Mobile Augmented Reality Issues in Informing Science and Information Technology, 11(1): 001-011.

Adrianto, D., Hidajat, M., and Yesmaya, V. 2017. Augmented Reality Using Vuforia for Marketing Residence 2016 1st International Conference on Game, Game Art, and Gamification ICGGAG : 1-5.

Sural, I. 2018. Augmented Reality Experience: Initial Perceptions of Higher Education Students International Journal of Instruction, 11(4): 565-576.

Ahmadi, R. A., Adler, J., and Ginting, S. L. 2017. Teknologi Augmented Reality sebagai Media Pembelajaran Gerakan Shalat. Prosiding Seminar Nasional Komputer dan Informatika (SENASKI): 179-186.

Suran, K. 2014. QR Code Image Correction based on Corner Detection and Convex Hull Algorithm. Journal of Multimedia, 9(5): 662-668

Aisyah, Bukit N., and Derlina. 2020. Blended Learning on Physics Using Augmented Reality. Journal of Physics: Conference Series, 1485(1): 01200

Arifitama, B., Syahputra, A., Permana, S. D. H., and Bintoro, K. B. Y. 2019. Mobile Augmented Reality for Learning Traditional Culture Using Marker Based Tracking. IOP Conference Series: Materials Science and Engineering, 662(2): 022038. 
Bostanci, E., Kanwal, N., Ehsan, S., and Clark, A. F. 2013. User Tracking Methods for Augmented Reality. International Journal of Computer Theory and Engineering, 5(1): 93-98.

Liu1, X., Sohn, Y. H., \& Park, D. W. 2018. Application Development with Augmented Reality Technique using Unity 3D and Vuforia. International Journal of Applied Engineering Research, 13(21): 15068-15071.

Alper, A., Öztaş, E. Ş., Atun, H., Çınar, D., \& Moyenga, M. 2021. A systematic literature review towards the research of game-based learning with augmented reality. International Journal of Technology in Education and Science, 5(2): 224-244.

Köse, H., \& Güner-Yildiz, N. 2021. Augmented reality (AR) as a learning material in special needs education. Education and Information Technologies, 26(2): 1921-1936. 